\title{
A visual method for direct selection of high-producing Pichia pastoris clones
}

\author{
Fan $\mathrm{Hu}^{1+}$, Xin $\mathrm{Li}^{2+}$, Jie Lü ${ }^{3}$, Pei Hong Mao ${ }^{3}$, Xiang $\mathrm{Jin}^{3}$, Ben Rao ${ }^{1}$, Peng Zheng ${ }^{1}$, Yu Lin Zhou', Sheng Yi Liu², \\ Tao Ke ${ }^{4}$, Xiang Dong $\mathrm{Ma}^{1 *}$, Li Xin $\mathrm{Ma}^{1}$
}

\begin{abstract}
Background: The methylotrophic yeast, Pichia pastoris, offers the possibility to generate a high amount of recombinant proteins in a fast and easy way to use expression system. Being a single-celled microorganism, $P$. pastoris is easy to manipulate and grows rapidly on inexpensive media at high cell densities. A simple and direct method for the selection of high-producing clones can dramatically enhance the whole production process along with significant decrease in production costs.
\end{abstract}

Results: A visual method for rapid selection of high-producing clones based on mannanase reporter system was developed. The study explained that it was possible to use mannanase activity as a measure of the expression level of the protein of interest. High-producing target protein clones were directly selected based on the size of hydrolysis holes in the selected plate. As an example, the target gene (9elp-hal18) was expressed and purified in Pichia pastoris using this technology.

Conclusions: A novel methodology is proposed for obtaining the high-producing clones of proteins of interest, based on the mannanase reporter system. This system may be adapted to other microorganisms, such as Saccharomyces cerevisiae for the selection of clones.

\section{Background}

Recently, the methylotrophic yeast Pichia pastoris is used for high level production of recombinant proteins for basic research and medical applications [1-4]. Many heterologous proteins have been successfully expressed in Pichia pastoris due to its exceptional natural capacity for heterologous protein production http://www.kgi.edu/ Faculty-and-Research/James-M-Cregg.html. Escherichia coli can produce large amounts of heterologous protein, but due to the difference in protein folding environment and inability to perform posttranslational modifications, it fails to deliver correctly folded functional protein. Whereas Pichia pastoris eukaryotic system has been used successfully for non-expressible proteins in E. coli [5]. The main advantage of Pichia over E. coli is to produce disulfide bonds and glycosylations in proteins; this means that in cases where disulfides are necessary, $E$.

\footnotetext{
* Correspondence: mabo1978@163.com

+ Contributed equally

'Hubei Key Laboratory of Industrial Biotechnology, College of Life Science,

Hubei University, Wuhan, 430062, PR China

Full list of author information is available at the end of the article
}

coli might produce a misfolded protein that is usually inactive or insoluble.

Yeasts differ substantially from higher eukaryotes in post-translational modification, especially in glycosylation. Saccharomyces cerevisiae glycosylation pattern usually results in hyperglycosylated inactive proteins [6,7]. Pichia pastoris strains have been re-engineered to overcome this undesired glycan modification [5]. Availability of new strains with mammalian-type glycosylation capabities has made $P$. pastoris more important for the industrial production of therapeutic proteins [8]. Optimization of protein yield, which is primarily determined by protein expression levels, is a very important costsaving area. A good screening and selection method for high-producing Pichia pastoris clones certainly help to lower the costs significantly.

The major method to select the high-producing recombinants in yeast is to use the antibiotic resistance genes. Mostly yeast expression vectors contain dominant drug resistance markers which allow enrichment of strains with multiple copies of foreign gene expression cassettes. It is deliberated that vectors contains the
C Biomed Central

(c) 2011 Hu et al; licensee BioMed Central Ltd. This is an Open Access article distributed under the terms of the Creative Commons Attribution License (http://creativecommons.org/licenses/by/2.0), which permits unrestricted use, distribution, and reproduction in any medium, provided the original work is properly cited. 
bacterial kanamycin resistance gene confer dose-dependent resistance to the antibiotic G418 in $P$. pastoris transformants [9], whereas some series of vectors which contains the Sh ble gene confer dose-dependent resistance to the antibiotic Zeocin. Selection of multi-copy transformants is usually performed, after the primary selection of transformants on plates, containing different concentrations of antibiotic. However, there are limitations of this method as: $(i)$ the number of colonies screened by antibiotic is limited to approximately 100 , (ii) The higher vector copy number does not always result in the higher protein yield, the protein expression level still needs to be determined. So, additional methods such as western blot analysis [9] or enzyme-linked immunosorbent assay (ELISA) $[10,11]$ are in dire need to determine the expression level of the protein. Consequently, more versatile system are required for rapid selection of high-producing clones.

In this critique, a novel method for rapid selection of high-producing clones based on the mannanase activity reporter system is emphasized. The role of target protein 9Elp-Hal18 has not been obviously studied in the $P$. pastoris. During the study a gene encoding 'mannanase' was selected as the reporter gene that was to be expressed with the gene for target protein 9Elp-Hal18, linked by short peptides Glu-Lys-Arg-Glu-Ala-Glu-Ala (EKREAEA) (recognized by the Kex2 and Ste13 protease) was investigated.

\section{Results}

\section{Construction of the recombinant expression vector pHBM306}

The recombinant plasmid pHBM305 was constructed by reverse PCR. The sequence of short peptides Glu-LysArg-Glu-Ala-Glu-Ala (EKREAEA) and the restriction enzyme sites was confirmed by Invitrogen Company. pHBM306 was constructed by inserting 9elp-hal18 gene between the Nde I and Not I restriction sites. Flow chart is given in Figure 1.

\section{Selection of the clones of different sizes for the mannanase activity analysis}

P. pastoris GS115 was transformed with linearized pHBM306 plasmid DNA and the recombinant transformants were first selected on minimal selective MD medium. These clones were transferred to the BMMY plates containing thypan blue which makes the plates look blue colored. Clear zone can be seen around mannanase expressing colonies which could hydrolyze the Konjac Glucomannan (KGM). Different sizes of hydrolysis holes were observed and measured after 24-48 hours of culturing (Figure 2). Twenty clones with different sizes of hydrolysis holes were measured and selected for the following enzyme activity assay. It is observed from the mannanase activity analysis that clones with larger clear zone correlate with higher mannanase activity (Figure 3).

\section{Purification, characterization and SDS-PAGE analysis of fusion protein}

For further confirmation, four clones with different diameter of holes for the following mannanase activity assay and target protein assay were selected. The supernatant of each fermentation broth was analyzed by SDS-PAGE after 120 hours of culturing. Results clearly demonstrate successful separation of the reporter and target protein with molecular mass evaluation of $\sim 42$ $\mathrm{kDa}$ and $\sim 40 \mathrm{kDa}$, respectively (Figure 4 ) and are well in consistence with the actual molecular masses. The target protein was also purified from the supernatant of fermentation broth by inverse transition cycle (ITC) procedure. The SDS-PAGE assay results demonstrated 9Elp-Hal18 was successfully purified with good purity (Figure 5).

Mannanase activity measurement was also executed for the clones selected in order to determine the quality of the target protein 9Elp-Hal18 which was purified from the supernatant of cultures. About $448.5 \mathrm{mg} / \mathrm{L}$ of 9Elp-Hal18 with $30 \mathrm{U} / \mathrm{ml}$ of mannanase activity(A), $336.7 \mathrm{mg} / \mathrm{L}$ of 9Elp-Hal18 with $26 \mathrm{U} / \mathrm{ml}$ of mannanase activity, $275.3 \mathrm{mg} / \mathrm{L}$ of $9 \mathrm{Elp}$-Hal18 with $20 \mathrm{U} / \mathrm{ml}$ of mannanase activity $(C)$ and $0.23 \mathrm{mg} / \mathrm{L}$ of 9Elp-Hal18 with $1.23 \mathrm{U} / \mathrm{ml}$ of mannanase activity (D), respectively were purified. These results clearly support our hypothesis that larger clear zone corresponds to high production of the target protein.

\section{Discussion}

The methylotrophic yeast $P$. pastoris has already been used successfully for the production of various recombinant heterologous proteins [12,13] and has been licensed to more than 120 companies in the biotechnological, pharmaceutical, animal health and food industries http://www.pichia.com. Some of the proteins are produced at grams per liter levels. Using the P. pastoris system to express foreign proteins has many advantages: The techniques needed for molecular genetic manipulation are similar to those well established for S. cerevisiae; $P$. pastoris can be easily grown to high cell densities using defined minimal media and is able to introduce eukaryotic posttranslational modifications; Distribution and chain length of N-linked oligosaccharides are different from those of $S$. cerevisiae. For instance, the chain length is significantly shorter, making it an interesting alternative for the extra-cellular expression of human proteins [14]; Complex proteins such as human glycoproteins or human collagens are also successfully processed and secreted by $P$. pastoris [15-18]; Another advantage of the $P$. pastoris expression system 


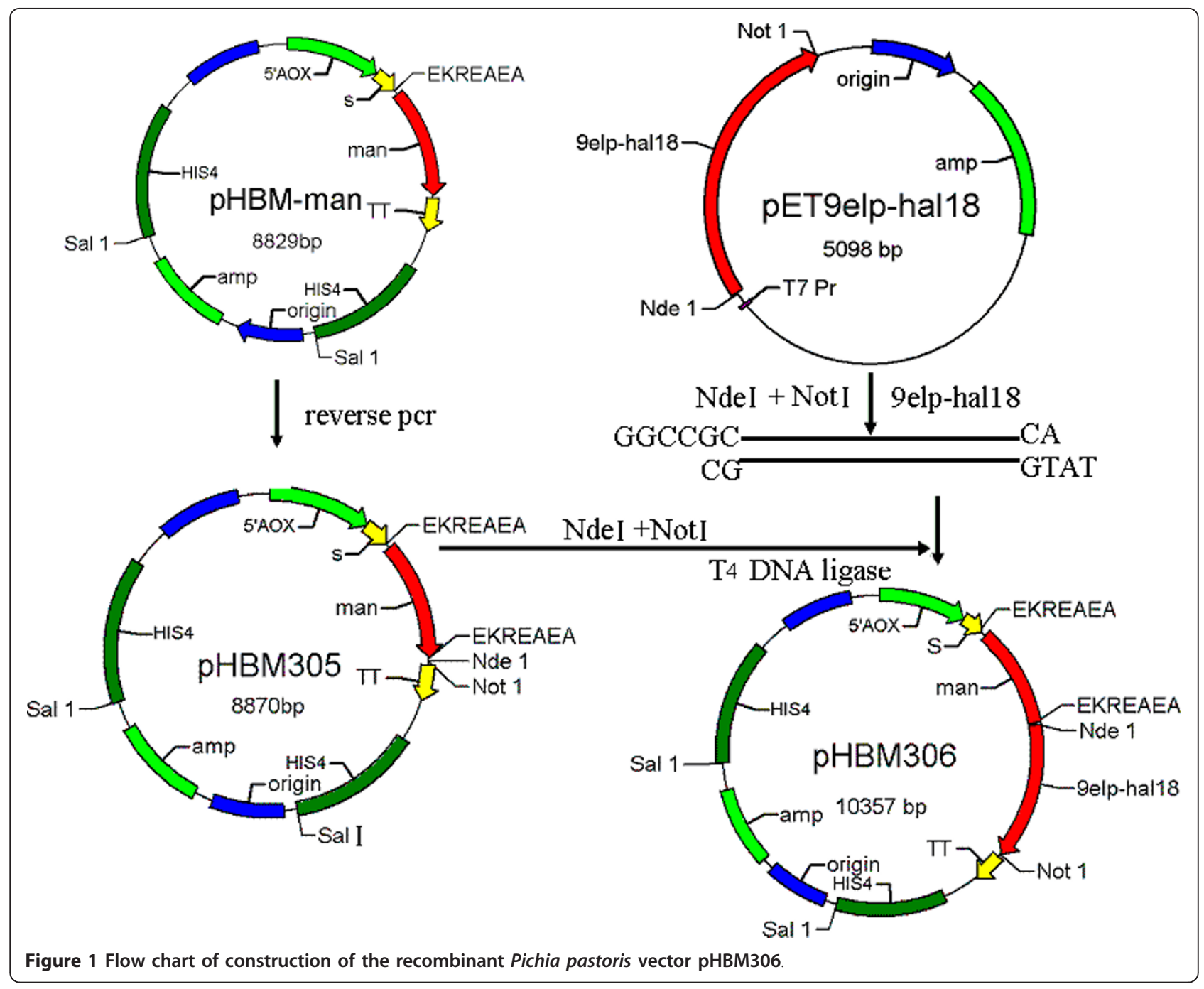

is the secretion of foreign proteins into culture media which making it convenient to obtain large amounts of foreign proteins in a relatively pure form without the contamination of cellular proteins. With the availability of new genetically engineered strains that show mammalian-type glycosylation, interest in using $P$. pastoris for the industrial production of therapeutic proteins has increased even further. So a good method for the screening and selection of high-producing transformants is certainly very useful that will ultimately decrease the cost of the industrial production.

The concept of a mannanase reporter system is to use the mannanase activity as a measure of the expression levels of a protein of interest. This can be achieved by integrating the reporter gene (mannanase) and the gene of interest under the same promoter, from where they can be expressed proportionally. We cloned the fusion protein expression cassette into the pHBM305 vector, resulting in pHBM306 expression vector (Figure 1). In both the pHBM305 and the modified pHBM306 plasmids, the HIS4 selection marker was used for selection of stable integrants based on complementation of $P$. pastoris HIS4 mutant strains. For the fusion protein expression, the AOX1 promoter was used for expression of the protein of interest [19]. During the protein secretion pathway, the fusion protein was separated by the cleavage of the kex 2 and ste 13 protease. Results also show that the marker protein is separated from the target protein (Figure 4) and the mannanase activity is proportional to the target protein expression level. The enzyme activity assay also clearly showed that the bigger hydrolysis hole is correlated with high activity of clone. It is concluded that the activity of the mannanase or the size of hydrolysis hole is a measure of the 9Elp-Hal18 expression because it has a positive correlation with quantity of the target protein.

Compared with other selection methods, such as using antibiotics, G418 or Zeocin for selecting the multi-copy 


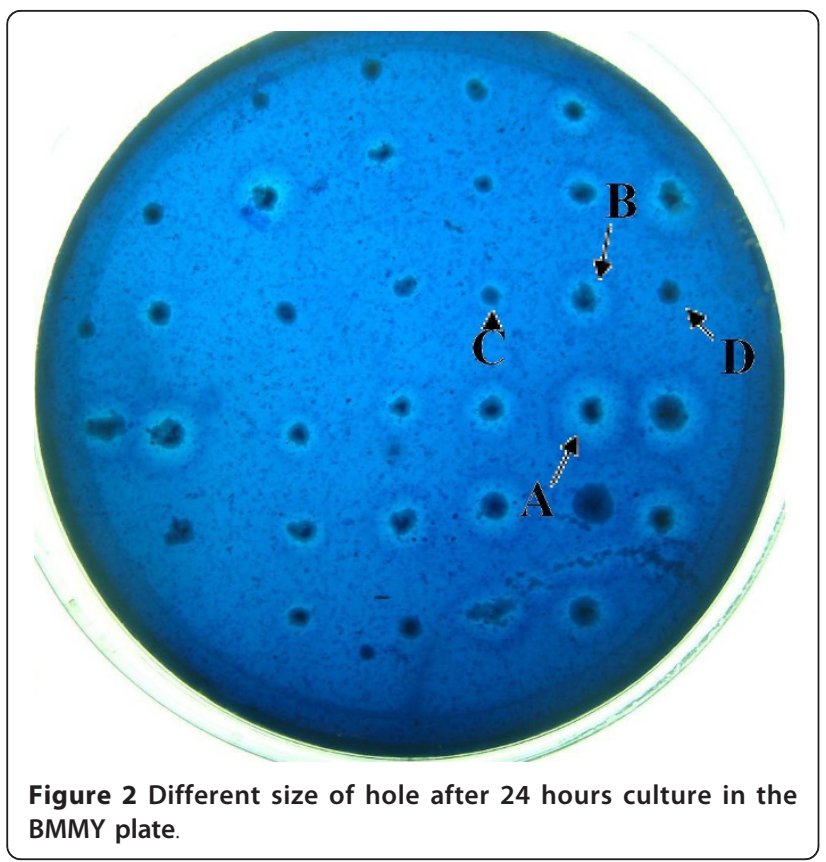

clones, the mannanase reporter system has several advantages in screening high-producing clones. First, it's bio-safe and eliminates the need for antibiotics as well as of enzyme-linked immunosorbent assay and western blot analysis, which are time-consuming and expensive techniques. Second, it is a high-throughput selection method, which can efficiently select thousands of clones at one time, in contrast with the antibiotic screening, which is limited to approximately 100 clones at a time. Third, it can be screened and selected directly by the clear zones or hydrolysis holes in the plate. The bigger holes corresponding to high-producing clones. Also this screening system has potential to give more output [20] when combined with multi-copy in vivo fusion of the

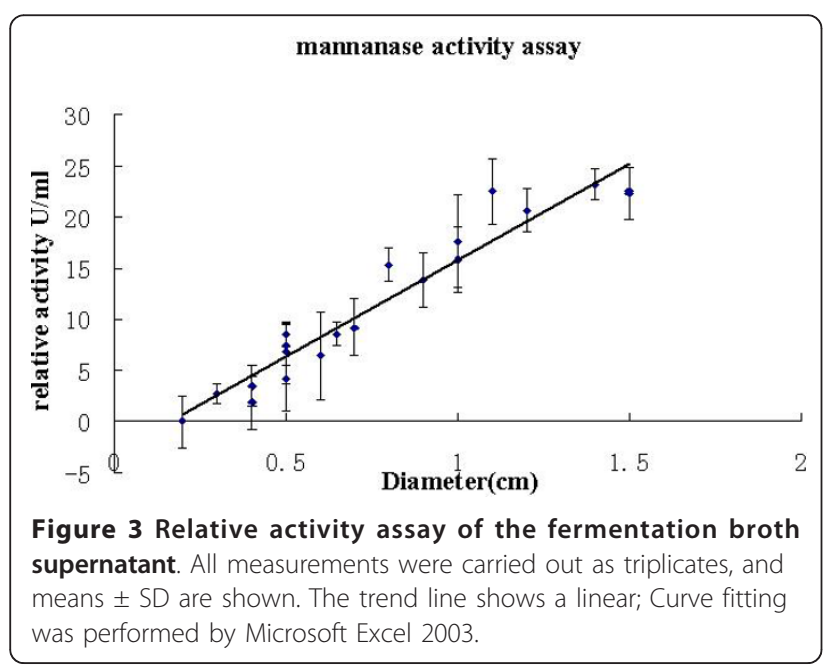

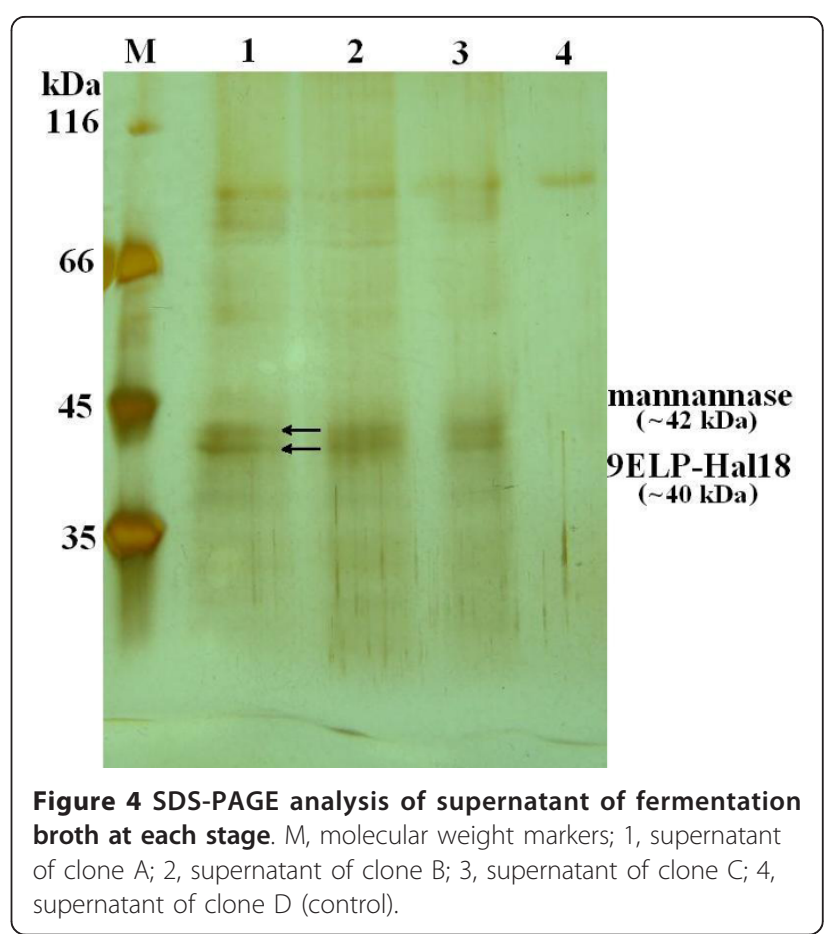

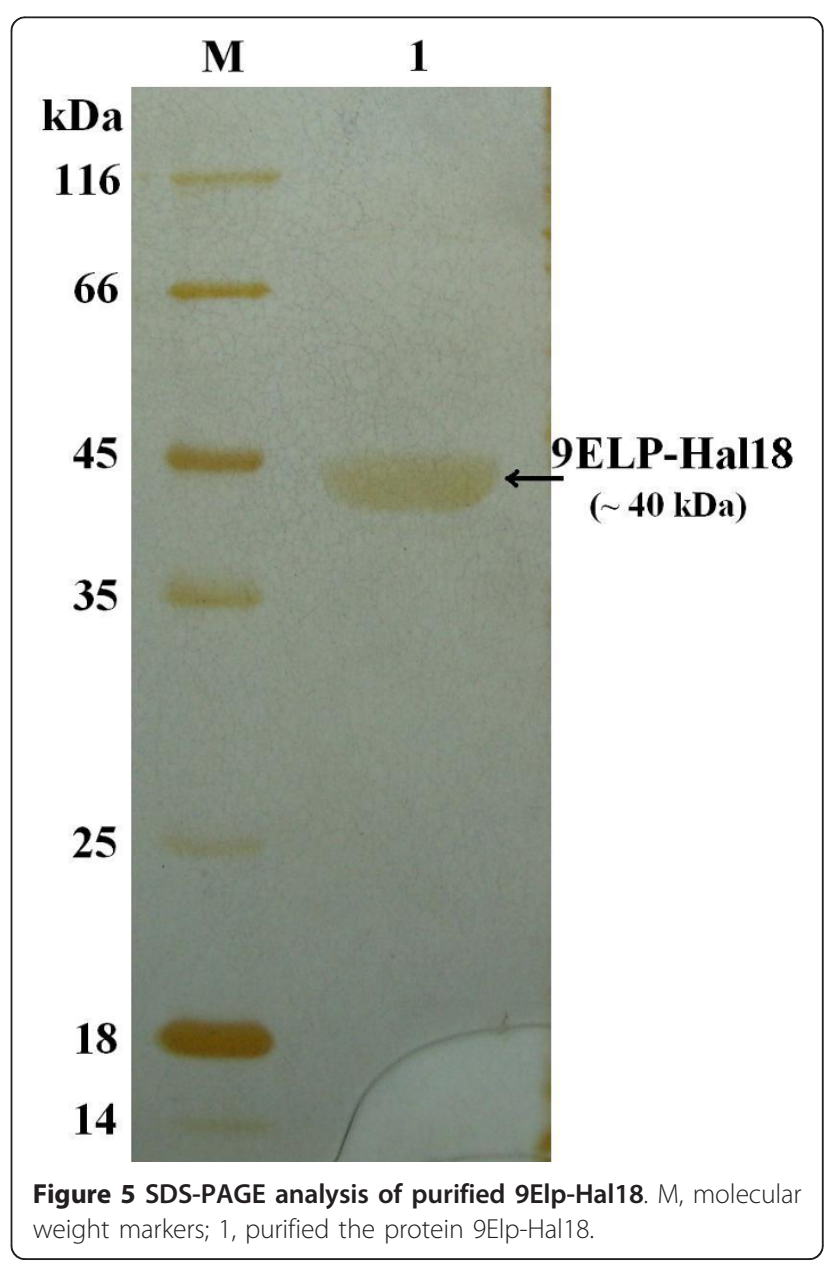


genes in a head to tail pattern. We intend to conduct these experiments in our future research work.

When deciding that protein secretion is the preferred approach to be used for a particular target protein, a choice of the specific secretion signal must be made [20]. This selection can be based on the protein's own native secretion signal (if it has one), the $S$. cerevisiae alpha -mating factor pre -pro leader sequence $(\alpha-M F)$, the acid phosphatase signal sequence (PHO) or the invertase signal sequence (SUC2) [20,21]. The most commonly used signal sequence in $P$. pastoris secretion systems is the $S$. cerevisiae alpha -mating factor pre -pro leader sequence. Although the $\alpha$-MF pre -pro sequence has been used extensively. There are some instances where its application has been problematic. The main reason is due to the insertion of Glu-Ala dipeptide repeats between the amino-terminus of the mature recombinant protein and the Kex $2 p$ cleavage site. Although the Glu-Ala repeats do improve the proportion of correctly cleaved material by preventing steric hindrance of the kex2p cleavage site $[20,22]$. Their presence results in the generation of a recombinant protein with Glu-Ala amino terminal extensions. This can lead to N-terminal ragged ends due to differential amino-terminal processing because of the inability of the ste $13 p$ to process the large quantity of recombinant protein that is being produced $[20,23]$. As the presence of these amino-terminal dipeptide extensions is undesirable for many recombinant protein applications, the Glu-Ala repeats between the mature protein and the kex $2 p$ can be omitted as part of the cloning approach in order to achieve a more authentic amino-terminus. Omission of these Glu-Ala repeats, however, can result in a decreased efficiency in the Kex2p cleavage specificity. In this case, secretion of the pro-protein cleavage products that have long aminoterminal extensions corresponding to 9-11 amino acids of the $\alpha$-MF pro-region has been observed $[20,24]$. This can be an issue when producing biopharmaceuticals. The one possible way to solve this problem is to treat fermentation broth by adding the purified Kex2 protease in vitro [25].

\section{Conclusions}

In heterologous protein production, fast and inexpensive screening processes are desperately required to reduce the production cost of recombinant proteins. The Pichia pastoris products will eventually appear in the market and the use of this mannanase reporter system is obviously a valuable substitution method for time consuming and expensive selection techniques. The results clearly demonstrate that this visual method brings about rapid selection of high-producing clones for expression of secretary recombinant proteins. Furthermore, such reporter system can be easily applied to other industrially important yeast expression systems.

\section{Methods}

\section{Strains and plasmids}

E. coli XL10-GOLD (Stratagene, La Jolla, CA) was used to construct the recombinant plasmids. P. pastoris GS115 strain, genotype his4 (Invitrogen, Carlsbad, CA, USA), was used for yeast transformation and protein expression. pHBM-man [obtained from our own lab] was used to construct the expression vector pHB306. Vector pET-9elp-hal18 constructed in a previous research work contained the gene for the target protein (9Elp-Hal18) and Konjac Glucomannan (KGM) was used as the mannanase hydrolysis substrate.

\section{Construction of expression plasmid}

Short peptides Glu-Lys-Arg-Glu-Ala-Glu-Ala and two restriction sites, Nde I and Not I were added at the ends of the mannanase gene by reverse PCR. Product of 9elphal18 gene was selected as the target protein to evaluate the new reporter system. 9elp-hal18 gene was obtained from the plasmid pET-9elp-hal18 by restriction digestion at the Nde I and Not I sites. These were cloned between the same restriction sites in the plasmid pHBM305. This new recombinant plasmid was designated as pHBM306.

\section{Yeast Transformation}

pHBM306 plasmid DNA $(10 \mu \mathrm{g})$ was linearized by using Sal I restriction enzyme to delete ampicillin resistance gene and the origin of E. coli. P. pastoris cells were transformed with the linearized plasmid DNA by electroporation method according to the protocol given in Pichia Expression kit manual. Yeast cells were grown in yeast extract-peptone-glucose (YPD) medium following the manufacturer's recommendations. Plasmid pHBM905 was used to prepare the control strain.

\section{Mannanase Activity Assay of the clones with different sizes of clear zone}

Linearized pHBM306 was transformed into P. pastoris GS115 and integrated at the P. pastoris HIS4 locus. Transformants were first selected on minimal selective MD medium $\left(0.34 \% \mathrm{YNB}, 4 \times 10^{-5} \%\right.$ biotin, $1 \%$ dextrose, and $1.5 \%$ agar) and then transferred to the BMMY plates (100 mM potassium phosphate, $\mathrm{pH} 6.0,0.34 \%$ YNB, $4 \times 10^{-5} \%$ biotin, $0.5 \%$ methanol, $1 \%$ yeast extract, $2 \%$ peptone) containing $1 \%$ KGM and $0.02 \%$ Thypan blue. After 24-48 hours, hydrolysis holes of different sizes could be observed in the culture plates. Twenty clones with different sizes of hydrolysis holes were measured and selected for the following enzyme activity assay. 
Prior to mannanase activity measurement on plate directly, twenty clones with different sizes were selected from BMMY with KGM added and were inoculated in $50 \mathrm{ml}$ BMGY medium (1\% glycerol replaced by $0.5 \%$ methanol in BMMY) in a $500 \mathrm{ml}$ shake flask. These cultures were centrifuged when optical density reached 20 (equivalent to $1 \times 10^{9}$ cells $\left./ \mathrm{ml}\right)$, at $600 \mathrm{~nm}\left(\mathrm{OD}_{600}\right)$. The cell mass was re-suspended to $25 \mathrm{ml}$ BMMY medium to induce recombinant mannanase expression. These cultures were grown for 120 hours at a temperature of $28^{\circ}$ $\mathrm{C}$ while shaking at $250 \mathrm{rpm}$. Mannanase activity in culture supernatants was assayed after 120 hours culture. It was determined by measuring the amount of reducing sugars liberated during the hydrolysis of KGM by the dinitrosalicylic acid method [26]. The standard assay reaction mixture consisted of $3 \%(\mathrm{w} / \mathrm{v})$ of polysaccharide substrates supplemented with $50 \mathrm{mM}$ sodium citrate buffer ( $\mathrm{pH}$ 6.0) and enzyme to make a final volume of $0.3 \mathrm{ml}$. The reaction mixture was incubated at $55^{\circ} \mathrm{C}$ for 15 min because one unit of enzyme produced $1 \mu \mathrm{mol}$ of reducing sugar per min.

\section{Purification, characterization and SDS-PAGE analysis of 9Elp-Hal18}

Target protein concentration was also measured for the colonies selected to determine Mannanase activity. Target protein 9Elp-Hal18 was purified from the supernatant of the cultures after 120 hours. Due to the unique properties of Elp fusion protein, 9Elp-Hal18 can be easily separated and purified from mannanase and other contaminating proteins, from the supernatant by inverse transition cycle (ITC) procedure (a very simple method for purification of recombinant proteins) $[27,28]$. Target protein was purified from the supernatant of fermentation broth was mixed with protein sample buffer $(0.5 \mathrm{M}$ Tris-HCl [pH 6.8], 10\% glycerol, $5 \%$ sodium dodecyl sulfate [SDS], $5 \% \beta$-mercaptoethanol, $0.25 \%$ bromophenol blue), heated to $100^{\circ} \mathrm{C}$ for $5 \mathrm{~min}$ and then subjected to $12 \%(w / v)$ SDS-polyacrylamide gel electrophoresis (SDSPAGE). The protein bands were detected by silver staining. Protein concentrations were measured using MicroBCA Protein Assay Reagent (Pierce, USA).

\footnotetext{
Acknowledgements

This work was supported by the National Natural Science Fund of China (No.30960006), the grants from the China National Human Liver Proteomics Project (2004BA711A19) and the China National High-Tech 863 Program (2006AA02A310).

Author details

${ }^{1}$ Hubei Key Laboratory of Industrial Biotechnology, College of Life Science, Hubei University, Wuhan, 430062, PR China. ${ }^{2}$ Oil Crops Research Institute, Chinese Academy of Agricultural Sciences, Wuhan, 430062, PR China. ${ }^{3}$ Institute of Ion Beam Biotechnology, College of Physics Science and Technology, Xinjiang University, Urumqi, 830008, PR China. ${ }^{4}$ College of Life
}

Science and Technology, Nanyang Normal University, Nanyang 473061, PR China.

\section{Authors' contributions}

$\mathrm{FH}, \mathrm{XL}$, conceived of the study, participated in its design and carried out the molecular genetic studies; $J$, participated in the sequence alignment and draws the vector maps; PHM, XJ performed the statistical analysis; BR, PZ carried out the enzyme activity assay; YLZ, SYL, TK, have been involved in drafting the manuscript and revising it critically for important intellectual content; XDM, LXM have given final approval of the version to be published. All authors read and approved the final manuscript.

Received: 9 August 2010 Accepted: 21 March 2011

Published: 21 March 2011

\section{References}

1. Romanos MA, Scorer CA, Clare JJ: Foreign gene expression in yeast. Yeast 1992, 8:423-488.

2. Cregg JM, Vedvick TS, Raschke WC: Recent advances in the expression of foreign genes in Pichia pastoris. Bio/Technology 1993, 11:905-910.

3. Cereghino JL, Cregg JM: Heterologous protein expression in the methylotrophic yeast Pichia pastoris. FEMS Microbiol Rev 2000, 24(1):45-66.

4. Faber KN, Harder W, Ab G, Veenhuis M: Review: methylotrophic yeasts as factories for the production of foreign proteins. Yeast 1995, 11(14):1331-1344.

5. Monsalve RI, LU G, King TP: Expression of recombinant venom allergen, antigen 5 of yellojacket (Vespula vulgaris) and Paper Wasp (Polistes annularis), in bacteria or yeast. Protein Expr Purif 1999, 16:410-416.

6. Schutter KD, Lin YC, Tiels P, Hecke AV, Glinka S, Lehmann J W, Rouze P, Peer YVD, Callewaert N: Genome sequence of the recombinant protein production host Pichia pastoris. Nature Biotechnology 2009, 27:561-569.

7. Lee CCW, Tina G, Wong DWS, Robertson GH: An episomal expression vector for screening mutant gene libraries in Pichia pastoris. Plasmid 2005, 54:80-85.

8. Hamilton SR, Davidson RC, Sethuraman N, Nett JH, Jiang $Y$, Rios $S$, Bobrowicz P, Stadheim TA: Humanization of yeast to produce complex terminally sialylated glycoproteins. Science 2006, 313:1441-1443.

9. Scorer CA, Clare JJ, McCombie WR, Romanos MA, Sreekrishna K: Rapid selection using G418 of high copy number transformants of Pichia pastoris for high-level foreign gene expression. Bio/Technology (NY) 1994, 12:181-184.

10. Boettner M, Prinz B, Holz C, Stahl U, Lang C: High-throughput screening for expression of heterologous proteins in the yeast Pichia pastoris. $J$ Biotechnol 2002, 99(1):51-62.

11. Gabrielle ZL, Nadia C, Christoph R, Franc P, Renaud W: Dot-blot immunodetection as a versatile and high-throughput assay to evaluate recombinant GPCRs produced in the yeast Pichia pastoris. Protein Expr Purif 2006, 50(1):118-127.

12. Macauley PS, Fazenda ML, MCNeil B, Harvey LM: Heterologous protein production using the Pichia pastoris expression system. Yeast 2005, 22:249-270.

13. Cregg JM, Cereghino JL, Shi J, Higgins DR: Recombinant protein expression in Pichia pastoris. Mol Biotechnol 2000, 16:23-52.

14. Grinna LS, Tschopp JF: Size distribution and general structural features of $\mathrm{N}$-linked oligosaccharides from the methylotrophic yeast, Pichia pastoris. Yeast 1989, 5(2):107-115.

15. Hamilton SR, Bobrowicz P, Bobrowicz B, Davidson RC, Li H, Mitchell T, Nett JH, Rausch S, Stadheim TA, Wischnewski H, Wildt S, Gerngross TU: Production of complex human glycoproteins in yeast. Science 2003, 301:1244-1246.

16. Choi BK, Bobrowicz P, Davidson RC, Hamilton SR, Kung DH, Li H, Miele RG, Nett JH, Wildt S, Gerngross TU: Use of combinatorial genetic libraries to humanize $\mathrm{N}$-linked glycosylation in the yeast Pichia pastoris. Proc Natl Aca Sci 2003, 100:5022-5027.

17. Li H, Sethuraman N, Stadheim TA, Zha D, Prinz B, Ballew N, Bobrowicz P, Choi BK, Cook WJ, Cukan M, Houston CNR, Davidson R, Gong B, Hamilton SR, Hoopes JP, Jiang Y, Kim N, Mansfield R, Nett JH, Rios S, Strawbridge R, Wildt S, Gerngross TU: Optimization of humanized IgGs in glycoengineered Pichia pastoris. Nature Biotechnology 2006, 24:210-215.

18. Pakkanen O, Haemaelaeinen ER, Kivirikko Kl, Myllyharju J: Assembly of stable human type I and III collagen molecules from hydroxylated 
recombinant chains in the yeast Pichia pastoris: Effect of an engineered C-terminal oligomerization domain foldon. J Biol Chem 2003, 278:32478-32483.

19. Sears IB, Connor JO, Rossanese OW, Glick BS: A versatile set of vectors for constitutive and regulated gene expression in Pichia pastoris. Yeast 1998, 14:783-790.

20. Rachel D, Milton TWH: Review: Expression of heterologous proteins in Pichia pastoris: a useful experimental tool in protein engineering and production. J Mol Recognit 2005, 18:119-138.

21. Li PZ, Go XG, Arellano RO, Renugopalakrishnan V: Glycosylated and phosphorylated proteins-expression in yeast and oocytes of Xenopus: prospects and challenges-relevance to expression of thermostable proteins. Protein Expr Purif 2001, 22:369-380.

22. Sreekrishna K, Brankamp RG, Kropp KE, Blankenship DT, Tsay JT, Smith PL, Wierschke JD, Subramaniam A, Birkenberger LA: Strategies for optimal synthesis and secretion of heterologous proteins in the methylotrophic yeast Pichia pastoris. Gene 1997, 190:55-62.

23. Brake AJ, Merryweather JP, Coit DG, Heberlein UA, Masiarz FR, Mullenbach GT, Urdea MS, Valenzuela P, Barr PJ: Alpha-factor-directed synthesis and secretion of mature foreign proteins in Saccharomyces cerevisiae. Proc Natl Acad of Sci USA 1984, 81:4642-4646.

24. Henkel MK, Pott G, Henkel AW, Juliano L, Kam CM, Powers JC, Franzusoff A: Endocytic delivery of intramolecularly quenched substrates and inhibitors to the intracellular yeast Kex2 protease. Biochem J 1999, 341:445-452.

25. Franzusoff A, Volpe AM, Josse D, Pichuantes S, Wolf JR: Biochemical and genetic definition of the cellular protease required for HIV-1 gp160 processing. The Journal Of Biological Chemistry 1995, 7(270):3154-3159.

26. Miller ML. Blum R, Glennon WE, Burton AL: Measurement of carboxymethylcellulase activity. Anal Biochem 1960, 2:127-132.

27. Hu F, Ke T, Li X, Mao PH, Jin X, Hui FL, Ma XD, Ma LX: Expression and Purification of an Antimicrobial Peptide by Fusion with Elastin-like Polypeptides in Escherichia coli. Appl Biochem Biotechnol 2010, 160(8):2377-2387.

28. Li B, Daggett V: The molecular basis for temperature- and $\mathrm{pH}$-induced conformational transitions in elastin-based peptides. Biopolymers 2003, 68:121-129.

doi:10.1186/1472-6750-11-23

Cite this article as: Hu et al:: A visual method for direct selection of high-producing Pichia pastoris clones. BMC Biotechnology 2011 11:23.

\section{Submit your next manuscript to BioMed Central and take full advantage of:}

- Convenient online submission

- Thorough peer review

- No space constraints or color figure charges

- Immediate publication on acceptance

- Inclusion in PubMed, CAS, Scopus and Google Scholar

- Research which is freely available for redistribution

Submit your manuscript at www.biomedcentral.com/submit 